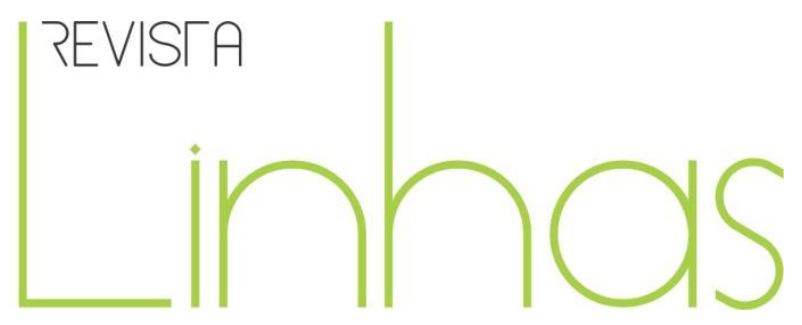

\title{
O ensino de música nas escolas estaduais de Santa Catarina da Grande Florianópolis: uma análise com base no ciclo de políticas
}

\section{Resumo}

Este artigo apresenta dados relacionados à pesquisa de mestrado intitulada A implementação da Lei n. 11.769/2008: um estudo na rede estadual de Santa Catarina com foco na Grande Florianópolis, que teve como objetivo compreender a inserção da música como conteúdo curricular obrigatório nas escolas estaduais de Santa Catarina, depois da aprovação da Lei n. 11.769/2008. A abordagem qualitativa com um estudo de caso foi utilizada como metodologia. A coleta de dados se deu através de entrevistas e grupos focais. Os representantes das gerências regionais de educação (Gered) e o representante da Secretara de Educação (SED) consideram que a música faz parte da disciplina de Arte. Os professores, por sua vez, reforçam que a lei foi importante, porém, não trouxe modificações para a implementação da música como conteúdo obrigatório na área de Arte. Segundo a abordagem do ciclo de políticas, no contexto da prática, os professores e demais profissionais exercem o papel de interpretação e reinterpretação das políticas. Sendo assim, o que acreditam e o que pensam têm um papel fundamental na implantação ou não das políticas educacionais. Os resultados apontam que, nas escolas estaduais, as aulas de Arte ainda acontecem de forma polivalente.

Palavras-chave: Educação Musical. Professores de Arte. Ciclo de Políticas.
Helena Vasconcelos

Universidade do Estado de Santa Catarina - UDESC -

Florianópolis/SC - Brasil helenavgv@gmail.com

\section{Regina Finck Schambeck}

Universidade do Estado de Santa

Catarina - UDESC -

Florianópolis/SC - Brasil regina.finck@udesc.br

\footnotetext{
Para citar este artigo:

VASCONCELOS, Helena; SCHAMBECK, Regina Finck. O ensino de música nas escolas estaduais de Santa Catarina da Grande Florianópolis: uma análise com base no ciclo de políticas. Revista Linhas. Florianópolis, v. 20, n. 42, p. 63-85, jan./abr. 2019.
} 


\title{
The teaching of music in the state schools of Santa Catarina (greater Florianópolis): an analysis based on a policy cycle
}

\begin{abstract}
This article examines the data related to a master's dissertation with the title: "The implementation of Law No. 11.769/2008: a study in the State network of Santa Catarina with a focus on Greater Florianópolis". The purpose of this study was to understand the way music has been incorporated in the Curriculum of the State schools of Santa Caterina as a compulsory subject, following the enactment of Law No. 11.769/2008. The methodology involved adopting a qualitative approach and employing a case study. The data collection took place through interviews and focal groups. The representatives of the Department of Regional Education Management (GERED) and the representative of the Secretary for Education (SED) all regard music as forming a part of the subject of Art. The teachers, in turn, stressed that although the Law was important, it did not make any alterations to the way music was taught as a compulsory subject in the area of the Arts. Following the approach adopted in the policy cycle, in their everyday practice, teachers and other professionals play a role in both interpreting and reinterpreting policies. In view of this, what they believe and what they think, plays a crucial role in their decision about whether or not to introduce the educational policies. The results show that lessons on Art in the State schools, still take place in a multipurpose way.
\end{abstract}

Keywords: Musical Education. Art Teachers. Policy Cycle. 


\section{Introdução}

Este artigo está relacionado à pesquisa de mestrado que investigou a implementação do ensino de música em escolas da rede estadual de educação de Santa Catarina, intitulada A implementação da Lei n. 11.769/2008: um estudo na rede estadual de educação de Santa Catarina com foco na Grande Florianópolis. Buscou-se compreender como aconteceu a inserção da música como conteúdo curricular obrigatório nas escolas dessa rede, depois da aprovação da Lei n. 11.769, de 18 de agosto de 2008 (BRASIL, 2018). A coleta de dados da pesquisa foi realizada entre os anos de 2014 e 2015, sendo que seus resultados foram apresentados em março de 2016. No processo da pesquisa, permearam discussões sobre a inserção da música como conteúdo obrigatório nas aulas de Arte das escolas estaduais de Santa Catarina da Grande Florianópolis. Essas discussões estavam pautadas na referida lei, porém, em maio de 2016, foi aprovada a Lei n. 13.278 , de 2 de maio de 2016, que alterou o sexto parágrafo do artigo 26 da LDB de 1996, com relação ao ensino de Arte (parágrafo segundo): "As artes visuais, a dança, a música e o teatro são linguagens que constituirão o componente curricular de que trata o $\S 2^{\circ}$ deste artigo." (BRASIL, 2016). Assim, a Lei n. 11.769/2008 foi substituída pela Lei n. 13.278/16, porém, a música continua sendo conteúdo obrigatório da área de Arte na educação básica. O texto da nova lei incluiu as outras áreas de Arte, deixando mais claro que todas elas constituem esse componente curricular, o que torna atuais e pertinentes as discussões sobre a inserção da música na escola, na perspectiva de compreender o que pensam os profissionais gestores e também professores que ministram essa disciplina, no contexto investigado, sobre a obrigatoriedade do ensino de música.

Neste artigo, apresentam-se os resultados obtidos com os professores habilitados em música, que são efetivos ${ }^{1}$ e atuam na disciplina Arte, em relação à condução de suas aulas, a fim de também identificar se houve reflexos da Lei n. 11.769/2008 para as discussões na área de Arte no estado de Santa Catarina e ampliar outras discussões, em relação ao entendimento que os gestores da SED ${ }^{2}$ e da Gered ${ }^{3}$ possuem sobre os termos

\footnotetext{
${ }^{1}$ Professores efetivos são aqueles que mantêm vínculo permanente com a instituição de ensino, mediante a realização de concurso público.

${ }^{2}$ A SED - Secretaria de Estado da Educação é o órgão responsável pela administração e orientação do ensino público do Estado de Santa Catarina. Disponível em: <http://www.sed.sc.gov.br>. Acesso em: 10 set.
} 
polivalência e interdisciplinaridade. Entende-se aqui que o posicionamento desses profissionais pode ajudar na compreensão do percurso atual da implantação do ensino de música nesses contextos.

A abordagem qualitativa com a utilização do estudo de caso foi usada na pesquisa como metodologia norteadora. Considera-se como unidade de caso a implementação da Lei n. 11.768/2008. Para entender o processo dessa implementação, procurou-se por informações das diferentes instâncias relacionadas à área da educação no estado de Santa Catarina, como a SED, a Gered e os professores efetivos habilitados em música da gerência da Grande Florianópolis.

A coleta de dados foi feita através de entrevistas individuais com os professores, com o assessor da educação básica, representante da SED, e com grupos focais de professores gestores, representantes das Gereds. Para as análises da pesquisa, usamos a abordagem do ciclo de políticas, elaborado por Stephen Ball e Richard Bowe, pesquisadores ingleses na área de políticas educacionais. Segundo Mainardes (2007), essa abordagem apresenta elementos para a análise da trajetória da implementação de políticas educacionais. Os dois pesquisadores propuseram cinco contextos que englobam desde os estágios iniciais até a análise dos resultados e efeitos da implementação da lei.

De maneira geral, o representante da SED e os representantes das Gereds consideram que a música faz parte da disciplina Arte. Contudo, não se considera o fato de que o professor da disciplina, com formação específica, é responsável por todas as áreas que constituem o componente curricular Arte. Tanto que os professores entrevistados na pesquisa disseram considerar que a Lei n. 11.769/2008 foi, sim, importante para a área da música, porém, eles não perceberam modificações no tratamento dado para a área de Arte nas escolas estaduais do estado de Santa Catarina, mesmo com a obrigatoriedade de conteúdos de música previstos pela Lei n. 13.278/16.

2018.

${ }^{3}$ A Gered - Gerência Regional de Educação é um órgão da Secretaria de Estado da Educação de Santa Catarina, é responsável pelas escolas de um determinado número de municípios. Disponível em: <http://www.sed.sc.gov.br/secretaria/gerencias-regionais-de-educacao>. Acesso em: 10 set. 2018. 


\section{Organização da disciplina arte no contexto ds escolas estaduais de Santa Catarina}

No que diz respeito à Secretaria de Estado da Educação, Santa Catarina, em 2018, está dividida em 21 unidades de gerências regionais (Gered), que administram 1.229 escolas de educação básica, distribuídas em seus 295 municípios.

Representando a SED, foi entrevistado o assessor da educação básica, que argumentou que a música faz parte do componente curricular Arte, porém, os concursos públicos e editais de contratação para professores não contemplam a área de formação licenciatura em Música; e que os editais lançados para a contratação de profissionais da educação são direcionados para a grande área, que define o campo de conhecimento humano como Educação Artística ${ }^{4}$, sem a menção às diferentes linguagens que envolvem o componente curricular Arte.

Para dar mais clareza, destaca-se que no edital n. $21 / 2012^{5}$, que previa o ingresso no magistério, a titulação exigida previa diploma e histórico escolar de conclusão de curso superior de licenciatura plena em Artes ou em Educação Artística. Segundo as diretrizes curriculares nacionais do curso de graduação em Música, estabelecida pelo Conselho Nacional de Educação, a nomenclatura dos cursos de formação é Licenciatura em Música, o que não era contemplado no referido edital. Diferentemente, o edital n. 24/2015 ${ }^{6}$ para a contratação de professores admitidos em caráter temporário (ACT), publicado em 4 de setembro de 2015, previa as linguagens específicas da área de Arte: Artes Visuais e Artes Plásticas, Artes Cênicas ou Teatro, Música e Dança. Isso repercutiu favoravelmente junto às instituições formadoras que oferecem cursos de Arte em suas diferentes habilitações, reparando-se, assim, o entendimento restritivo para os licenciados em Música, como vinha sendo adotado pela SED em relação aos títulos exigidos para a contratação dos professores em editais anteriores.

\footnotetext{
${ }^{4}$ O parecer do CNE/CEB n. 22/2005 prevê a substituição do nome Educação Artística por Arte, com base na formação específica plena em uma das linguagens: Artes Visuais, Dança, Música e Teatro.

${ }^{5}$ Disponível em: <http://www.sed.sc.gov.br/documentos/concurso-ingresso-2012-magisterio-337/1318-editaln-21-2012-concurso-ingresso-magisterio-2399/file>. Acesso em: 10 set. 2018.

6 Disponível em: <http://www.sed.sc.gov.br/documentos/recursos-humanos-161/act-188/act-2016576/cronograma-gered/cacador/4194-cronograma-2016-cacador/file>. Acesso em: 10 set. 2018.
} 
Assim, na análise do edital 21/2012, percebeu-se que, na contratação daqueles professores, não houve preocupação com a garantia de que todas as linguagens fossem contempladas na distribuição da disciplina Arte na matriz curricular. Porém, segundo o assessor da educação básica, as escolas possuem autonomia para definir a habilitação do professor de Arte e, normalmente, isso deve estar definido no PPP (Projeto Político Pedagógico) de cada unidade escolar.

[...] o PPP é o projeto político pedagógico das escolas, é um documento fundamental para as escolas, embora elas não tenham compreendido isso ainda. Elas não tratam o PPP como sendo uma constituição, um documento 'mor' da escola. (Entrevista com assessor da educação básica, 4 ago. 2014)

Conforme explica o entrevistado, verifica-se que a escola possui autonomia para solicitar, junto à SED, os professores e a linguagem artística a serem adotados na escola.

No desenvolvimento da pesquisa, o cadastro funcional dos professores da Gered da Grande Florianópolis foi acessado. Nele, estavam registrados 119 professores efetivos que atuam na disciplina Arte. Desses, apenas quatro eram habilitados em Música. Ao ser questionada sobre essa inconsistência, a representante da Gered da Grande Florianópolis afirmou que a informação da habilitação dos professores não era relevante, pois os profissionais estavam cadastrados na disciplina Arte, não importando para a Gered o cadastro da habilitação individual de cada professor.

Diferentemente dessa afirmação dada pela representante de uma gerência educacional, acredita-se aqui que a habilitação do professor faz diferença na sua seleção e que a Arte deve ser pensada e organizada na rede, obedecendo-se as suas diferentes linguagens.

O assessor da educação básica também mencionou a autonomia das escolas para solicitar um professor com habilitação de sua preferência. Entende-se que essa autonomia gere ainda mais dificuldade para as unidades escolares, pois, no levantamento dos dados cadastrais, a falta de clareza das habilitações dos professores contratados dificulta a identificação dos licenciados em Música, caso alguma unidade queira um profissional com essa habilitação, por exemplo. Além disso, o número de professores efetivos para a disciplina Arte não contempla todas as escolas da rede estadual de 
educação, o que acarreta a contratação de professores em caráter temporário ${ }^{7}$. Assim, os professores de Arte, independentemente da sua habilitação, escolhem as escolas onde haja vaga para a atuação, não ocorrendo a escolha por uma habilitação específica, como explicou o assessor da educação básica, ao falar sobre a autonomia da escola.

Segundo a Proposta Curricular de Santa Catarina (SC, 1998), “[...] os conteúdos a serem abordados deverão contemplar uma postura interdisciplinar e devem corresponder às linguagens visual, cênica e musical. Isso significa dizer que o professor de Arte terá como ponto de partida, no seu planejamento, a linguagem específica de sua formação" (SANTA CATARINA. SECRETARIA DE ESTADO DA EDUCAÇÃO E DO DESPORTO, 1998, p. 194). Em 2014, houve atualização no texto da proposta e as disciplinas escolares foram agrupadas por áreas de conhecimento, sendo que a Arte ficou atrelada à área de conhecimento das Linguagens, juntamente com as Línguas e a Educação Física. Nesse novo documento, não há menção sobre a quem compete trabalhar cada linguagem artística, ficando subentendido que o professor de Arte deva trabalhar todas as linguagens artísticas.

Segundo a maioria dos representantes das Gereds entrevistadas, em relação à implementação da Lei n. 11.769/2008, ou seja, sobre a música na escola, a orientação da SED é a de que o professor de Arte trabalhe os conteúdos de música independentemente da sua habilitação. Ainda, a representante de uma Gered considerou que a música funciona como um tema transversal. Também, outras representantes consideraram que a música na escola seja importante, porém, questionam a falta de professores habilitados em música e a resistência dos professores de Arte em buscar por aprimoramento para atuar com conteúdos musicais. Outra representante considerou que a música na escola deveria estar vinculada ao projeto da escola de tempo integral, pois, como disciplina, sobrecarregaria ainda mais a matriz curricular. Outro representante comentou que, na sua Gered, não houve discussões sobre a implementação da Lei n. 11.769/2008, pois todos consideraram que esse conteúdo, a Música, já deveria ser trabalhado pelo professor de Arte.

\footnotetext{
7 De acordo com os dados de pesquisa apurados junto às Gereds de Santa Catarina, em 2018, o número de professores contratados em caráter temporário é de 158. Já o número de efetivos decresceu de 119, em 2015, para apenas 86, em 2018.
} 
Percebe-se, portanto, que os representantes das Gereds, a partir das colocações destacadas, apresentam certa diversidade de perspectivas em relação à música na escola. Também, a visão polivalente do ensino de Arte ainda está muito presente na rede estadual de Santa Catarina. A maioria dos participantes dos grupos focais afirmou que a música acontece na escola como atividade extracurricular vinculada ao programa Mais Educação $^{8}$, que estava em plena execução na época da coleta de dados e apresentava seu foco, principalmente, nas atividades culturais (entre elas, a música) e/ou de cunho esportivo.

\section{Professores(as) de música no contexto da disciplina de arte}

Para a realização da entrevista, foi elaborado um roteiro que teve por base o previsto na pesquisa comparativa das ações, práticas e metodologias de ensino de música

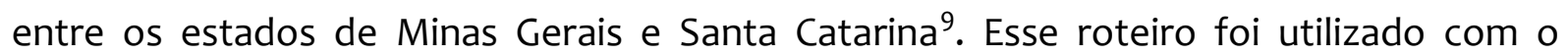
assessor da educação básica, o representante da SED e os representantes das Gereds. Para complementar os dados de coleta, foram entrevistados seis professores habilitados em Música, efetivos na disciplina Arte da Gered da Grande Florianópolis, aos quais foram aqui designados nomes fictícios.

A professora Rosa iniciou sua carreira como professora de Arte do Estado de Santa Catarina, por intermédio da admissão em caráter temporário (ACT), efetivando-se em 2004. Concluiu sua Licenciatura em Educação Artística, com Habilitação em Música através do programa Magister ${ }^{10}$. Rosa trabalhava com turmas do $9^{\circ}$ ano ao ensino médio

\footnotetext{
${ }^{8}$ O programa Mais Educação, estruturado pelo Ministério da Educação, constituía-se em uma estratégia para induzir a "[...] ampliação da jornada escolar e da organização curricular na perspectiva de educação Integral. Em 2017, o projeto foi reformulado através da Resolução FNDE nº 17/2017 e objetivava melhorar a aprendizagem de duas áreas: língua portuguesa e matemática no ensino fundamental. Em 2018, o programa foi implementado por meio da realização de acompanhamento pedagógico em Língua Portuguesa e Matemática e do desenvolvimento de atividades nos campos de Arte, cultura, esporte e lazer, impulsionando a melhoria do desempenho educacional mediante a complementação da carga horária em cinco ou quinze horas semanais, no turno e contraturno escolar". Disponível em: <http://portal.mec.gov.br/programa-mais-educacao >. Acesso em: 30 jul. 2018.
}

${ }^{9}$ A pesquisa A implementação da Lei n. 11.769/2008 no ensino fundamental das escolas públicas de Minas Gerais e Santa Catarina: um estudo comparativo das ações, práticas e metodologias de ensino da música foi realizada entre a Universidade do Estado de Santa Cataria (UDESC) e a Universidade Federal de Uberlândia (UFU), aprovada pelo Edital MCT/ CNPq n. 014/2013 - Universal.

${ }^{10}$ Através da Resolução n. 003/96 do Conselho Universitário (Consuni), foi homologado um convênio feito entre a UDESC e o Estado de Santa Catarina, através da SED, para a realização do Projeto Magister, que foi 
na disciplina de Arte, atuando com carga horária de 40 horas nessa disciplina e 20 horas como assistente técnico-pedagógica (ATP). Sua carga horária total, portanto, era de 60 horas semanais de trabalho.

O professor Eduardo terminou seu curso de Licenciatura em Artes com Habilitação em Música no ano de 2004. Em 2005, efetivou-se como professor de Arte no Estado de Santa Catarina, assumindo 40 horas semanais na mesma unidade por oito anos. Depois, alterou sua lotação para outra escola, onde atuava em turmas do ensino fundamental II e ensino médio.

O professor Gustavo terminou a Licenciatura em Educação Artística com Habilitação em Música no ano de 2000 e, em 2002, efetivou-se como professor de Arte com carga horária de 40 horas semanais, porém, depois de um ano e meio, reduziu sua carga horária para 30 horas. Possui mestrado em Música e atua na mesma escola desde a sua efetivação.

O professor Samuel terminou o curso de Licenciatura em Educação Artística com Habilitação em Música no ano de 2004. Trabalhou como professor substituto em outra instituição e prestou concurso público em 2012 para a disciplina de Arte, assumindo seu cargo em 2014. Tem carga horária de 30 horas semanais e atua com turmas do ensino fundamental I, II e ensino médio.

O professor Sidney terminou a licenciatura em Educação Artística com Habilitação em Música em 2004. Efetivou-se como professor de Arte no Estado de Santa Catarina no mesmo ano. Durante o período da coleta de dados, ele estava cursando a terceira fase do Bacharelado em Violão e exercendo a função de diretor da escola onde é efetivo.

A professora Lúcia terminou sua licenciatura em Educação Artística com Habilitação em Música em 1995. Em 2002, efetivou-se como professora de Arte e atuou

\footnotetext{
implantado para fazer frente à falta de professores com habilitação em cursos superiores de licenciaturas específicas para suas áreas de atuação na rede pública estadual e nas redes públicas municipais de ensino. A UDESC ofereceu dois cursos de formação inicial em Educação Artística - Habilitação em Música e em Artes Cênicas (de 1997 a 2002). O curso na área de Música teve início em dezembro de 1997, com o processo de vestibular realizado com professores da rede pública de alguns municípios do sul do estado. Dentre esses, foram aprovados 35, sendo que, desses, 26 se formaram em 22 de novembro de 2002. A professora Rosa foi uma desses formandos. (A Resolução n. 029/2002 está disponível em: <www.secon.udesc.br/consepe/resoldocs/2002/doc/029-2002-cpe.doc>. Acesso em: 10 set. 2018. A Resolução n. 003/07 está disponível em: <http://www.secon.udesc.br/consuni/resol/1997/003-97-cni.pdf>. Acesso em: 10 set. 2018.
} 
durante 11 anos na mesma escola. Em 2013, alterou sua lotação para outra escola. Sua carga horária é de 40 horas semanais.

Sobre a música na escola, o professor Samuel comenta que iniciou sua prática pedagógica após a aprovação da Lei n. 11.769/2008. Assim, ele não acompanhou o processo de discussões sobre a lei na escola. Samuel destaca que começou a trabalhar os conteúdos musicais e, por isso, logo foi chamado pelo coordenador pedagógico daquela unidade, recebendo a orientação de que não deveria trabalhar somente os conteúdos de música. A informação repassada era a de que a escola não tinha uma sala adequada e as atividades geravam barulho. Isso motivou protestos de outros professores. Outro fato mencionado pelo professor em sua entrevista foi que a escola onde ele atuava não possuía recursos para a compra de instrumentos musicais. Ele complementa que havia ainda a cobrança por parte da equipe pedagógica em relação aos conteúdos relacionados a outras áreas artísticas, como o desenho, por exemplo. Conforme a explanação dada pelo professor Samuel, percebe-se que a equipe pedagógica daquela unidade escolar esperava do professor uma postura polivalente, apesar da proposta curricular do Estado ter um direcionamento interdisciplinar.

A professora Rosa, por outro lado, considera a importância de se trabalhar de forma polivalente e disse que fazia seu planejamento em função disso. Segundo ela, é importante trabalhar dessa forma polivalente devido à formação do aluno. Rosa ainda justifica que alguns alunos não tinham possibilidade de ter experiências culturais fora do âmbito da escola e, assim, do seu ponto de vista, o trabalho polivalente permite que aluno vivencie e conheça diferentes áreas da Arte, como o teatro, a música e as artes visuais.

O professor Eduardo relatou que, no início do seu trabalho como professor de Arte, ele foi questionado sobre as atividades de outras áreas de Arte, como o desenho e a pintura. Para se posicionar frente a não aceitação de práticas polivalentes na área, Eduardo contou que elaborou um documento abordando a trajetória do ensino de Arte no Brasil. O documento em defesa da prática pedagógica direcionada apenas para conteúdos de música foi elaborado a partir dos preceitos da legislação, como a proposta curricular do Estado, os parâmetros curriculares nacionais, a LDB n. 9394/1996 e a Lei n. 11.769/2008. Além disso, ele organizou todo seu planejamento anual com base no 
documento que havia escrito e, mesmo assim, afirmou, precisava a toda hora reafirmar a importância do seu trabalho na área da sua habilitação para a equipe pedagógica da escola.

O professor Gustavo utilizou a Lei n. 11.769/2008 para reafirmar seu trabalho com música. No início da sua atuação profissional, ele também enfrentou dificuldades em relação à cobrança por parte da equipe pedagógica e até mesmo dos alunos, que lhe pediam para trabalhar outros conteúdos, como o desenho. Segundo contou, os alunos relacionavam a aula de Arte com aula de desenho. A estratégia adotada para diminuir as cobranças foi reduzir sua carga horária de trabalho e, paralelamente, fortalecer seu planejamento, de modo a trabalhar exclusivamente com conteúdos de música. Informou que, naquela época, pediu para que a equipe pedagógica começasse a assistir às suas aulas, para que ele pudesse demonstrar que era possível realizar um trabalho de qualidade apenas com a linguagem da sua habilitação. Segundo ele, isso lhe trouxe credibilidade.

A professora Lúcia considera que a Lei n. 11.769/2008 não modificou a forma como ela trabalha lecionando a disciplina de Arte. Ela explicou que atua de forma polivalente e que considera que a música já fazia parte dos conteúdos a serem abordados nas aulas. Portanto, a legislação não influenciou sua forma de ministrar as aulas, tampouco ela sofreu pressão por parte da equipe diretiva para mudar suas práticas pedagógicas. Lúcia informou ainda que, apesar de ter formação na área de Música, ela prefere trabalhar apenas conteúdos das Artes Visuais, fazendo ainda, esporadicamente, trabalhos manuais e/ou artesanato com seus alunos.

O professor Sidney relata a dificuldade de trabalhar somente com conteúdos de música. Justifica essa dificuldade pela falta de estrutura da escola, acrescentando como fator de dificuldade o pouco apoio recebido por parte da equipe pedagógica para fazer de outra forma. Como atuava com alunos do ensino médio, suas aulas tinham ênfase nos conteúdos de História da Música e História da Arte. Esse professor não fez menção para as atividades práticas. 


\section{Práticas polivalentes no contexto do ensino de arte}

Para abordar a questão da polivalência, toma-se aqui como ponto de partida a LDB n. 5.692/71, que inclui a Educação Artística como obrigatória nos currículos de $1^{\circ}$ e $2^{\circ}$ graus, conforme afirma Penna (2012, p. 123-124). Ainda segundo essa autora, a falta de clareza e de diretrizes sobre as especificidades dos conteúdos de cada linguagem deram margem para as práticas polivalentes dentro do contexto escolar. Essas práticas também têm relação com a formação dos professores dessa época. Segundo Penna (2012, p. 124),

[...] em 1973, são aprovados o Parecer CFE nº 1284/73 e a Resolução CFE $n^{\circ} 23 / 73$, termos normativos acerca do curso de licenciatura em Educação Artística, que estabelecem: a) a licenciatura de $1^{\circ}$ grau - que capacita para o exercício profissional neste nível de ensino, também chamada de licenciatura curta, em função de sua duração - que proporciona uma habilitação geral em Educação Artística, com base numa abordagem integrada das diversas linguagens artísticas; b) a licenciatura plena, que contempla essa habilitação geral a habilitações específicas, 'relacionadas com as grandes divisões da Arte' - Artes Plásticas, Artes Cênicas, Música e Desenho (nos termos do Parecer CFE n $1284 / 73$ - Brasil, 1982, p. 33-41). Essas linguagens artísticas passam a ser vistas como integrantes do campo da Educação Artística.

Considera-se que a própria formação do professor de Educação Artística dessa época contribuiu para o aparecimento das práticas polivalentes, pois se pensava que todas as áreas faziam parte da Educação Artística. De acordo com Penna (2012), não seria possível que um professor com curso de licenciatura com duração de dois anos desse conta da quantidade de conteúdos que cada uma das linguagens envolve.

Sobre a formação desse modelo de licenciatura, Barbosa (1988, p. 66) fazia críticas veementes:

Infelizmente, muito pouco podemos esperar dos cursos de graduação em Educação Artística que pretendem formar o professor polivalente. Este professor sai, depois de dois anos de curso universitário, incapaz de se expressar adequadamente em qualquer das linguagens (música, teatro, dança, artes plásticas, desenho), que supostamente pode ensinar [...]. A integração de linguagem que estes cursos pretendem não passa de justaposição periférica, como ouvir uma música e desenhar o que sentiu ao ouvi-la ou ilustrar um poema. 
Para Barbosa (2017, p. 9) a concepção da polivalência adotada pelo Brasil teve origem no modelo americano, ou seja, na realidade brasileira houve um processo de redução daquele modelo que, adaptado para um país pobre, criou a figura "absurda" do professor polivalente:

[...] evidentemente, não deu certo [...], as universidades advertiram imediatamente acerca do absurdo epistemológico de se querer formar arremedos de Leonardo da Vinci no século XX.

A prática polivalente, segundo Penna (2007, p. 2), marcou o início da Educação Artística e contribuiu para a superficialidade dos conteúdos de cada linguagem, tendo em vista que um professor deveria trabalhar com todas as linguagens:

[...] o esvaziamento dos conteúdos próprios de cada linguagem artística, promovido pela prática e formação polivalente na Educação Artística, foi intensamente discutido na academia e nos encontros da área, inclusive nos congressos da FAEB/ Federação de Artes Educadores do Brasil. Desde modo, foi-se consolidando a defesa da formação e da atuação nas áreas artísticas específicas, o que se refletiu, inclusive, no abandono do termo Educação Artística na atual Lei de Diretrizes e Bases da Educação Nacional (LDB) - Lei 9394/96.

A área de Arte buscava recuperar os conhecimentos específicos de cada uma das linguagens artísticas. Assim, na LDB n. 9394/96, foi alterado o termo Educação Artística para ensino de arte. O seu artigo 62 trata da formação de professores para atuar na educação básica, o que será feito “[...] em nível superior, em curso de licenciatura, de graduação plena, em universidades e institutos superiores de educação [...]" (BRASIL, 1996).

Em 2004, foram aprovadas as Diretrizes Curriculares Nacionais do curso de Graduação em Música (BRASIL, 2004). Segundo Penna (2012, p. 137), essas diretrizes

[...] têm caráter obrigatório, passando, portanto, a normatizar a formação docente [...] tais diretrizes implicam a transformação das licenciaturas plenas em Educação Artística (com habilitação em música) em licenciaturas em música, o que vem sendo realizado nas diversas instituições de ensino superior. 
O exposto por Penna $(2007 ; 2012)$ e por Barbosa $(1988 ; 2017)$ elucida os motivos das "raízes" da polivalência na escola. Porém, considerando a legislação atual para a área de Música, ou seja, as Diretrizes Curriculares Nacionais para os cursos de Graduação em Música (BRASIL, 2004) e a Lei n. 13.278/16, que especificou as áreas que fazem parte do componente curricular Arte, acredita-se aqui que quem deva assumir a disciplina Arte são professores habilitados em cada uma das áreas. Contudo, sabe-se que, por questões administrativas e financeiras, nem todas as redes de educação do Brasil possuem professores com habilitação específica de cada área artística para atuar em todas as escolas. No caso de Santa Catarina, não foi diferente.

Ao analisar a proposta curricular do Estado de Santa Catarina, identificaram-se, em seus fundamentos conceituais, além da presença dos conteúdos polivalentes para o professor, a adoção de uma abordagem interdisciplinar para área de Arte: “[...] os conteúdos a serem abordados deverão contemplar uma postura interdisciplinar e devem corresponder às linguagens visual, cênica e musical" (SANTA CATARINA. Secretaria de Estado da Educação e do Desporto, 1998, p. 187). Para compreensão do conceito de interdisciplinaridade, compartilha-se o apoio de Paviani, (2008, p. 7), que apresenta, com propriedade, a dualidade do termo:

[...] a interdisciplinaridade pode significar uma estratégia de flexibilização e integração das disciplinas, nos domínios do ensino e da produção de conhecimentos novos, da pesquisa, de outro lado ela pode tornar-se um mal entendido, especialmente quando é assumida como uma meta ou solução absoluta e autônoma, anulando totalmente a existência das disciplinas. Na realidade, a verdadeira interdisciplinaridade é uma defesa das disciplinas e não sua eliminação. Ela pode oferecer a compreensão, o limite e a função exata e adequada das disciplinas.

Considera-se, portanto, que dentro da área de Arte, na experiência do estado de Santa Catarina, há várias disciplinas, ou seja, há cada área da Arte separadamente, com suas especificidades, e que podem estar juntas em projetos e trabalhos interdisciplinares. Porém, para que isso ocorra de forma adequada, precisa-se de professores habilitados em cada área, pois, se isso não acontece, cai-se novamente na questão da polivalência, com a superficialidade dos conteúdos. 
Segundo Figueiredo (2017, p. 87), “[...] a interdisciplinaridade trazia como proposta uma nova perspectiva que enfrentasse a fragmentação curricular”. Conforme o autor, a interdisciplinaridade seria uma forma de suprir uma necessidade que a área de Arte estava enfrentando em relação à polivalência, já que essa prática trouxe de modo superficial conteúdos de cada linguagem artística. Portanto, a polivalência e interdisciplinaridade "[...] não são sinônimos, ou nomenclaturas diferentes para abordagens iguais. Há distinções claras na origem de tais conceitos e práticas". Argumenta ainda que "[...] o agrupamento das artes não representaria necessariamente uma prática interdisciplinar, pois não estaria contribuindo para uma nova abordagem que visaria a 'noção do todo', a integração, a superação da fragmentação curricular” (FIGUEIREDO, 2017, p. 87-88).

Assim, diferentemente do que foi apontado por Figueiredo (2017), conforme identificado nas entrevistas com o representante da SED e os representantes das Gereds, percebeu-se que designar um único professor como responsável pela disciplina de Arte, independentemente da sua habilitação, reforça o "[...] perverso efeito da polivalência no ensino de Arte" (BARBOSA, 2017, p. 4). Nesse sentido, a fala dos profissionais da SED e Gereds são contraditórias. Ao mesmo tempo em que muitos reforçaram que a Arte é importante na formação global, pois desenvolve a cognição do indivíduo, cognição essa que pode ser aplicada a outras áreas do conhecimento, por outro lado, poucos têm oportunizado a contratação, nas unidades escolares de suas coordenações, de professores para cada uma das quatro linguagens artísticas.

Assim, entende-se que a cobrança para que o professor de Arte trabalhe com todas as especificidades de cada linguagem artística tem duas razões principais. A primeira é a questão financeira, pois, ao invés de quatro professores, um apenas daria conta da carga horária da disciplina. A segunda questão seria de ordem administrativa, ou seja, carga horária reduzida de Arte na matriz curricular para preenchimento de horas a mais de disciplinas do eixo principal. Isso daria a falsa ideia de que a formação com ênfase nas aulas do eixo principal prepararia melhor esse aluno para o ensino médio, por exemplo. Como destaca Barbosa (2017), esse é um grande equívoco, pois, reduzindo-se as linguagens de Arte na matriz curricular, se está "reduzindo a possibilidade do 
desenvolvimento de habilidades importantes em outras disciplinas além das artes" (BARBOSA, 2017, p. 5).

\section{Práticas de ensino de música nas escolas do estado de Santa Catarina vistas sob o referencial do ciclo de políticas}

O ciclo de políticas, segundo Mainardes (2007), foi elaborado por Stephen Ball e Richard Bowe, pesquisadores ingleses na área de políticas educacionais. A abordagem do ciclo de políticas apresenta elementos para a análise da trajetória da implementação das políticas. Os pesquisadores propuseram cinco contextos que englobam desde os estágios inicias até a análise dos resultados e efeitos da implementação da lei. Segundo Mainardes (2006a), a abordagem do ciclo de políticas destaca

[...] a natureza complexa e controversa da política educacional, enfatiza os processos micropolíticos e a ação dos profissionais que lidam com as políticas no nível local e indica a necessidade de se articularem os processos macro e micro na análise de políticas educacionais. (MAINARDES, 2006a, p. 49)

Além disso, tal abordagem permite uma análise de políticas educacionais desde o início da sua formulação até a sua implementação. Portanto, esse referencial foi adotado porque se considera que a presente pesquisa está relacionada à área de políticas educacionais.

Conforme Mainardes (2006a), o ciclo de políticas foi proposto tendo, inicialmente, três contextos principais: o contexto da influência, o contexto da produção de texto e o contexto da prática. Depois de algum tempo, foi acrescentado ao ciclo de políticas mais dois contextos: o contexto dos resultados ou efeitos, e o contexto da estratégia política. A grande contribuição dessa abordagem é a de que os contextos estão "[...] interrelacionados, não têm uma dimensão temporal ou sequencial e não são etapas lineares" (MAINARDES, 2006a, p. 50).

O contexto da influência nessa abordagem é "[...] onde normalmente as políticas públicas são iniciadas e os discursos políticos são construídos" (MAINARDES, 2006a, p. 51). No contexto da influência, há uma disputa de poder, em que os grupos políticos e os 
grupos de interesses expõem seus posicionamentos de maneira a intervir nas formulações do discurso para a política. Os “[...] grupos de interesse disputam para influenciar a definição das finalidades sociais da educação" (MAINARDES, 2007, p. 29). Nesse contexto, conforme defende o autor, é que se forma o discurso de base para a política, por meio das influências e dos interesses específicos de comissões e grupos representativos da sociedade.

O contexto da produção de texto é a representação da política. "Os textos políticos, portanto, representam a política” (MAINARDES, 2006b, p. 97). A representação dessa política pode acontecer por textos oficiais, comentários formais ou informais, pronunciamentos e, até mesmo, vídeos.

No ciclo de políticas, segundo Lopes (2006, p. 38), “[...] a própria política deve ser entendida, simultaneamente, como discursos e como textos". A autora considera que:

[...] Ball entende os textos como representações que são codificadas e decodificadas de formas complexas, sofrendo múltiplas influencias [...] e os discursos como práticas que formam os objetos pelos quais falam e associam ao que pode ser dito, a quem pode dizer, quando e com que autoridade. (LOPES, 2006, p. 38)

Segundo Mainardes (2006b), as consequências dos textos políticos e da política como discurso acabam sendo vivenciadas no contexto da prática. Os autores do ciclo de políticas, segundo Mainardes (2006b), consideram que as políticas não são simplesmente implementadas no contexto da prática. Nesse contexto, as políticas também estão sujeitas a interpretações e podem ser reinterpretadas pelos profissionais que atuam no contexto da prática, pois eles analisam as políticas a partir da sua história, das suas crenças e de seus valores. A abordagem em questão assume que

[...] os professores e demais profissionais exercem um papel ativo no processo de interpretação e reinterpretação das políticas educacionais e, desta forma, o que eles pensam e acreditam têm implicações para o processo de implementação das políticas. (MAINARDES, 2006b, p. 98)

A política no contexto dos resultados ou efeitos deve ser analisada relacionando o seu impacto e as consequências ocasionadas onde a lei foi implementada. Pode-se, assim, 
observar o que foi alterado com a implementação da lei. No contexto de resultados ou efeitos, é importante salientar que a ideia de que a política não tem um resultado e, sim, efeitos, é mais apropriada. Nesse contexto,

[...] a análise de uma política deve envolver o exame (a) das várias facetas e dimensões de uma política e suas implicações [...] e (b) das interfaces da política com outras políticas setoriais e com o conjunto das políticas. Isso sugere ainda a necessidade de que as políticas locais ou as amostras de pesquisas sejam tomadas apenas como ponto de partida para a análise de questões mais amplas da política. (MAINARDES, 2006a, p. 54-55)

O contexto da estratégia política

[...] envolve a identificação de um conjunto de atividades sociais e políticas que seriam necessárias para lidar com as desigualdades criadas ou reproduzidas pela política investigada. (MAINARDES, 2006a, p. 55)

Pode-se considerar que, nesse contexto, estariam as mudanças que deveriam ser realizadas ou aquelas que já foram feitas para a efetivação da política proposta.

A abordagem do ciclo de políticas vem sendo utilizada em trabalhos da área de educação. Por esse motivo, foram consultados os gestores das Gereds e os professores na pesquisa de mestrado, principalmente sobre o contexto da prática, como aporte para as análises das entrevistas com o representante da SED.

O ciclo de políticas enfatiza a articulação entre os processos macro e micro para a análise das políticas educacionais. Assim, considera-se o assessor da educação básica, representante da SED, e os gestores das Gereds como a parte macro do processo de análise de políticas. Por outro lado, os professores efetivos, habilitados em Música e que atuam na disciplina de Arte da gerência regional do Estado de Santa Catarina, como a parte micro desse mesmo processo. 


\section{Considerações finais}

Neste artigo, apresentaram-se os resultados obtidos em pesquisa finalizada em 2016 com vistas a ampliar as discussões sobre a questão da polivalência e da interdisciplinaridade. Através das entrevistas com professores habilitados em Música que atuam na disciplina de Arte, com o assessor da educação básica, representando a SED, e com grupos focais formados por representantes das Gereds, elaborou-se este panorama aqui apresentado acerca da situação da Música nas escolas estaduais de Santa Catarina da região da Grande Florianópolis.

Conforme relatos dos professores entrevistados, do assessor e dos representantes das Gereds, conclui-se que a polivalência está ainda enraizada na cultura escolar da disciplina de Arte no Estado de Santa Catarina. Ao se relacionar as práticas atuais com a abordagem do ciclo de políticas, a parte macro está representada pela SED e Gereds, que elaboraram e mantêm a proposta curricular, e a parte micro, que engloba os professores, está presente na sala de aula. É possível perceber, portanto, que a cultura da polivalência no ensino de Arte se mantém no discurso dos participantes da pesquisa, mesmo que abolida a expressão educação artística, com a publicação da LDB n. 9.394 de 1996.

Poucos são os professores que conseguem, através da sua prática pedagógica, "quebrar esse círculo vicioso". Os professores continuam usando a polivalência porque interpretam a proposta desse jeito, e os representantes da SED e Gereds continuam cobrando essa prática, pois ainda não encontraram uma maneira diferente de lidar com todas as especificidades da área.

A proposta curricular de Santa Catarina propõe práticas interdisciplinares para o ensino de Arte, porém, percebe-se que há uma ambiguidade na interpretação em relação à polivalência e à interdisciplinaridade. Considera-se que, dentro da área de Arte, a interdisciplinaridade pode acontecer entre os professores de Arte de diferentes habilitações junto com professores de outras áreas, porém, cada um no seu campo de atuação, com as especificidades que cada componente do currículo apresenta.

Portanto, esperamos que os professores e representantes da SED, GERED e responsáveis pelas escolas possam ampliar os espaços para a educação musical na escola básica 
Portanto, esperamos que os professores e representantes da SED, GERED e responsáveis pelas escolas possam ampliar os espaços para a educação musical na escola bás

Dos seis professores entrevistados, que são habilitados em Música, dois trabalham exclusivamente com a linguagem musical, habilidade de sua formação. Outros dois professores usam a linguagem musical nas suas aulas, porém, enfrentam dificuldades para trabalhar somente com a música, por isso, acabam por incorporar no planejamento as outras linguagens artísticas. Diferentemente, os outros dois professores não dão ênfase em nenhuma das linguagens artísticas, trabalhando com todas elas de forma polivalente. Segundo esses professores, a recomendação da SED e das Gereds é a de que o professor de Arte trabalhe com todas as linguagens artísticas e procure dar ênfase à linguagem da sua habilitação. Portanto, estariam, assim, cumprindo uma determinação legal.

Em contrapartida, dois professores que não trabalham somente com a música argumentaram que os diretores das suas escolas exigem que o trabalho de Arte seja feito de forma polivalente. Esses dois professores justificaram isso explicando que os alunos ficariam prejudicados se somente a linguagem musical fosse trabalhada, pois, assim, não teriam a possibilidade de conhecer os conteúdos das outras linguagens, uma vez que, nas escolas, não há professores de diferentes habilitações para a mesma turma ou para turmas alternadas, conforme acontece em âmbito municipal em vários estados brasileiros. Nesses municípios, os professores são contratados nas suas habilidades específicas, podendo ocorrer simultaneamente a contratação de professores de diferentes habilitações para assumir as aulas de determinados anos escolares, possibilitando-se, assim, que os alunos tenham aulas das diferentes linguagens artísticas em cada ano escolar com professores especificamente habilitados. Um exemplo dessa prática é a do município de Florianópolis.

Por fim, os dois professores que trabalham somente com a linguagem da sua habilitação, a Música, destacaram que, nas suas unidades escolares, também havia a recomendação, por parte da direção da escola, para o trabalho polivalente. Eles mencionaram que, no início das suas carreiras profissionais, começaram a trabalhar de forma polivalente, como era pedido pela SED, Gereds e direção das unidades escolares. Porém, conquistaram, através do desenvolvimento do seu trabalho e de muita conversa 
com a direção daquelas unidades, a possibilidade de trabalhar somente com a linguagem da sua habilitação. Esse convencimento demostra que é possível, mesmo dentro de uma rede estadual que visa um trabalho de Arte com caráter polivalente, trabalhar somente com a habilitação específica.

De qualquer forma, esses professores conquistaram seu espaço dentro das suas unidades escolares, pois já atuavam nelas por muitos anos consecutivos. Esse fator é de extrema relevância ao se analisar o contexto da prática do ciclo de políticas, representado nesta pesquisa pelos professores, pois, segundo Ball (1987 apud LOPES; MACEDO, 2011, p. 265),

[...] a relativa autonomia dos professores sobre seu trabalho se deve à existência de disputas e negociações diversas na escola em torno do controle do trabalho docente. Os limites desse controle são modificados continuamente e dependem de enfrentamentos entre sujeitos e grupos das instituições.

Assim, quando o professor cria um vínculo de trabalho por anos numa mesma unidade escolar, ele consegue reafirmar o seu trabalho, obtendo o aval da equipe pedagógica e diretiva da escola em relação ao seu planejamento e práticas pedagógicas.

Acredita-se que a referida pesquisa contribui sobremaneira para a área de formação e prática de professores de Música, pois foi a primeira que se debruçou sobre as práticas desses professores na disciplina de Arte na Grande Florianópolis, no contexto das escolas estaduais de Santa Catarina.

Destaca-se, também, que garantias foram conquistadas, como se observou nos editais publicados pela SED de Santa Catarina, a partir do ano de 2016, que oportunizaram a participação e contratação de professores da Licenciatura em Música e da Licenciatura em Teatro, o que até então não estava ocorrendo.

Ressalta-se, por fim, que a inserção na estrutura física da Secretaria da Educação para a coleta de dados, in loco, permitiu o acesso a informações que de outra maneira, talvez, não fossem possíveis. Essa coleta demonstrou o quanto é díspar o ingresso de professores de Música para a admissão junto à rede estadual de Santa Catarina em relação às outras linguagens e evidencia, claramente, a hegemonia na contratação de professores das Artes Visuais. Fica claro nessa pesquisa que a macropolítica no ensino de 
Arte na rede estadual de Santa Catarina ainda é prevalente nas Artes Visuais em detrimento das outras linguagens, ao se considerar a formação dos professores contratados. Isso reforça a importância do movimento dos educadores musicais para a aprovação e implementação da Lei n. 11.769 e pela contratação equânime dos profissionais das diferentes linguagens da área de Arte.

\section{Referências}

BARBOSA, Ana Mae. O dilema das artes no ensino médio no Brasil. Pós: Revista do Programa de Pós-Graduação em Artes da EBA/UFMG, v. 7, n. 13, maio 2017. Disponível em: <https://eba.ufmg.br/revistapos>. Acesso em: 10 set. 2018.

BARBOSA, Ana Mae. Arte-educação: conflitos/acertos. 3. ed. São Paulo: Max Limonad, 1988.

BRASIL. Lei n. 11.769, de 18 de agosto de 2008. Altera a Lei n. 9.394, de 20 de dezembro de 1996, Lei de Diretrizes e Bases da Educação, para dispor sobre a obrigatoriedade do ensino da música na educação básica. 2008. Disponível em:

<http://www.planalto.gov.br/ccivil_03/_At02007-2010/2008/lei/L11769.htm>. Acesso em: 10 set. 2018.

BRASIL. Lei n. 13.278, de 2 de maio de 2016. Altera o parágrafo sexto do artigo 26 da Lei n. 9.394, de 20 de dezembro de 1996, que fixa as diretrizes e bases da educação nacional, referente ao ensino da arte. 2016. Disponível em:

<http://www2.camara.leg.br/legin/fed/lei/2016/lei-13278-2-maio-2016-782978-

publicacaooriginal-150222-pl.html>. Acesso em: 10 set. 2018.

BRASIL. Lei n. 9.394, de 20 de dezembro de 1996 - Lei de Diretrizes e Bases da Educação Nacional. 1996. Disponível em: <http://www.planalto.gov.br/ccivil_03/leis/l9394.htm>. Acesso em: 10 set. 2018.

BRASIL. Resolução n. 2, de 8 de março de 2004. Aprova as Diretrizes Curriculares Nacionais do Curso de Graduação em Música e dá outras providências. Disponível em: <http://portal.mec.gov.br/cne/arquivos/pdf/CES02-04.pdf>. Acesso em: 10 set. 2018.

FIGUEIREDO, Sergio Luiz Ferreira de. A música e as artes na formação do pedagogo: polivalência ou interdisciplinaridade? Revista FAEEBA - Educação e Contemporaneidade, Salvador, v. 26, n. 48, p. 79-96, jan./abr. 2017.

LOPES, Alice Casimiro. Discursos nas políticas de currículo. Currículo sem Fronteiras, v. 6, p. 33-52, 2006. Disponível em: <http://www.curriculosemfronteiras.org>. Acesso em: 10 set. 2018.

LOPES, Alice Casimiro; MACEDO, Elizabeth. Contribuições de Stephen Ball para o estudo de políticas de currículo. In: BALL, Stephen J.; MAINARDES, Jeferson. Políticas educacionais. São Paulo: Cortez Editora, 2011. p. 248 - 275. 
MAINARDES, Jefferson. Abordagem do ciclo de políticas: uma contribuição para análise de políticas educacionais. Educação \& Sociedade, Campinas, v. 27, n. 94, p. 47-69, jan./abr., 2006a. Disponível em: <http://www.scielo.br/pdf/es/v27n94/a03v27n94.pdf>. Acesso em: 10 set. 2018.

MAINARDES, Jefferson. A abordagem do ciclo de políticas e suas contribuições para a análise da trajetória de políticas educacionais. Atos da pesquisa em educação, Blumenau, v. 1, n. 2, p. 94 - 105, maio/ago., 2006b. Disponível em:

<http://proxy.furb.br/ojs/index.php/atosdepesquisa/article/view/34>. Acesso em: 10 set. 2018.

MAINARDES, Jefferson. Reinterpretando os ciclos de aprendizagem. São Paulo: Cortez Editora, 2007.

PAVIANI, Jayme. Interdisciplinaridade: conceitos e distinções. 2. ed. Caxias do Sul/RS: Educs, 2008.

PENNA, Maura. Professores de música nas escolas públicas de ensino fundamental e médio: uma ausência significativa. Revista da Abem, n. 7, p. 7-19, 2002.

PENNA, Maura. A formação inicial do professor de música: por que uma licenciatura? In:CONGRESSO NACIONAL DA FEDERAÇÃO DE ARTES EDUCADORES DO BRASIL, CONFAEB, XVII. 2007. Anais... Disponível em:

<http://aaesc.udesc.br/confaeb/main.php?l=lista_anais>. Acesso em: 10 set. 2018.

PENNA, Maura. Música(s) e seu ensino. 2. ed. Porto Alegre: Sulina, 2012.

SANTA CATARINA. Secretaria de Estado da Educação e do Desporto. Proposta Curricular. 1998. Disponível em: <http://www.sed.sc.gov.br/documentos/ensino-89/propostacurricular-156/1998-158/formacao-docente-233/282-proposta-curricular-formacao-docenteed-infantil-series-iniciais-640/file>. Acesso em: 10 set. 2018.

SANTA CATARINA. Secretaria de Estado da Educação e do Desporto. Edital n. 21, de 6 de agosto de 2012. Disponível em:

<http://www.sed.sc.gov.br/secretaria/documentos/doc_download/2399-edital-no-212012concurso-ingresso-magisterio $>$. Acesso em: 10 set. 2018.

SANTA CATARINA. Secretaria de Estado da Educação e do Desporto. Edital n. 24, de 2015. Disponível em:

<http://downloads.acafe.org.br/download/concursos/sed_2016/editais/Edital_ACT_2016_E DUC_BAS_OFICIAL_SED_3.pdf >. Acesso em: 10 set. 2018.

Recebido em: 05/09/2018 Aprovado em: 22/11/2018

Universidade do Estado de Santa Catarina - UDESC Programa de Pós-Graduação em Educação - PPGE Revista Linhas

Volume 20 - Número 42- Ano 2019 revistalinhas@gmail.com 